\title{
What Can We Learn from the History of Nordic Computing?
}

\section{Summary of Panel Discussion}

\author{
Discussants: Harold (Bud) Lawson (Sweden), Søren Duus Østergaard (Denmark), \\ Ingeborg Torvik Sølvberg (Norway), and Nina Wormbs (Sweden)
}

\section{Moderator: Tomas Ohlin (Sweden)}

The panel discussion took place during the second day of the conference. Professor Hans Andersin (Finland) had planned to participate but was unable to do so. Historian Dr. Lars Ilshammar (Sweden) was invited to participate with prepared questions for the panel.

The panel members had prepared introductory statements that expressed specific comments about the historical development. In regard to this, before the conference, Hans Andersin had distributed comments addressing the role of cooperation with government in forming an information society that would otherwise, to a great extent, have turned out to be guided by university research and industrial achievements.

At the start of the session, the panel members were given time to make introductory comments. The panel addressed the limited role of women's activities in the development of computing as well as the role of the type of education given during that time. With a different type of education, could the development have been different?

The panel noted the challenge of the increasing complexity of systems developed from early times and onwards. Did this lead to a complexity that was too great and unstable, and if so, what can be done? It also pointed out that there can be different types of historical lessons learnt depending on who is being taught. Some lessons address the needs and practices of applied research; others are structural and address cooperation, or relate to specific achievements in industry and, to some extent, the broader society.

A discussion followed between the members of the panel. Comments were made about the role of education for early development, and about the varying rates of progress during different historical phases. What types of external conditions had been instrumental for the different phases?

Lars Ilshammar added comments regarding who questioned how possible lessons learnt could be of value for further historical research after pointing out the experiences gained from three HINC conferences. Is there need for increased methodological refinement? He added that as computing has become increasingly transnational over time cooperation over borders may become more relevant, inviting more comparative approaches. Ilshammar also added that it may be of interest to question how Nordic activities had contributed to the view on information systems in which systems structures have changed from standby computers to ever-enhancing networks. 
With this as background, panelists commented about the role of computing history as an emerging new field of research and the possibility of finding value from more established scientific fields with historical contact.

It was then noted that early Nordic computing development had, to some extent, reaped some benefits from certain types of governmental support, and surely also from cooperation between industry, education, and research. However, central parts of the development of Nordic computer systems can hardly be said to have been the sole fruit of explicit governmental planning.

After a number of remarks from the panel, the discussion was opened up for comments and questions from the public. Numerous aspects were added, among them observing the importance of lessons learnt from insufficient concern about systems security and supporting compatibility between system dialects.

In a review of the points made during the panel discussion, certain aspects were emphasized. These often took the form of questions rather than answers:

- How can we address the concept of Nordic influence in a situation where the Nordic countries acted separately, to some extent?

- Was there a geographically related type of influence, concerning shared responsibility?

- Did the Nordic computing mentality (e.g., cooperation in systems work and user influence) transcend internationally?

- What role can historians play in the further analysis of computing development in an information society?

- Could the Nordic influence have taken a different path if computing scientists and engineers allocated greater concern to computing security in its early stages of development?

In summarizing the panel discussion, we note that the discussion raised more questions than answers provided. For future endeavors, statements were made about the importance of specific types of education that already start at elementary school. The need for increased security concern was also noted. Comments were added about the importance of a more evident gender balance in different phases of the historical development. These comments are important for future types of analyses, where lessons from the past may be a historical ladder upward and forward. A concluding remark of the panel discussion was as follows:

The Nordic countries are now part of the world, a situation where cooperation may be of increased value. It is worth remembering that we are only at the beginning of a movement into the online society, a development that contains much change. 